Article

\title{
Synthesis of New 2,5-Di-substituted 1,3,4-Oxadiazoles Bearing 2,6-Di-tert-butylphenol Moieties and Evaluation of Their Antioxidant Activity
}

\author{
Raied M. Shakir ${ }^{1,2}$, Azhar Ariffin ${ }^{1, *}$ and Mahmood Ameen Abdulla ${ }^{3}$ \\ 1 Department of Chemistry, Faculty of Science, University of Malaya, Kuala Lumpur 50603, \\ Malaysia; E-Mail: raiedalsayab@yahoo.co.uk \\ 2 Department of Chemistry, Ibn Al-haitham, University of Baghdad, Baghdad 61023, Iraq \\ 3 Department of Molecular Medicine, Faculty of Medicine, University of Malaya, \\ Kuala Lumpur 50603, Malaysia; E-Mail: ammeen@um.edu.my \\ * Author to whom correspondence should be addressed; E-Mail: azhar70@um.edu.my; \\ Tel.: +60-3-7967-4080; Fax: +60-3-7967-4193.
}

Received: 7 February 2014; in revised form: 11 March 2014 / Accepted: 12 March 2014 / Published: 20 March 2014

\begin{abstract}
Eleven new 2,6-di-tert-butyl-4-(5-aryl-1,3,4-oxadiazol-2-yl)phenols 5a-k were synthesized by reacting aryl hydrazides with 3,5-di-tert butyl 4-hydroxybenzoic acid in the presence of phosphorus oxychloride. The resulting compounds were characterized based on their IR, ${ }^{1} \mathrm{H}-\mathrm{NMR},{ }^{13} \mathrm{C}-\mathrm{NMR}$, and HRMS data. 2,2-Diphenyl-1-picrylhydrazide (DPPH) and ferric reducing antioxidant power (FRAP) assays were used to test the antioxidant properties of the compounds. Compounds $\mathbf{5 f}$ and $\mathbf{5} \mathbf{j}$ exhibited significant free-radical scavenging ability in both assays.
\end{abstract}

Keywords: 2,6-di-tert-butylphenol; hindered phenol; antioxidant; 1,3,4-oxadiazole; FRAP; DPPH

\section{Introduction}

Phenolic antioxidants inhibit or prevent oxidative stress in biological systems. Free radicals are one of the main causes of many pathological conditions such as those that cause several degenerative [1] and chronic diseases [2]. Furthermore, numerous heterocyclic compounds containing di-tert-butyl phenol exhibit various types of biological activity in addition to their antioxidant ability $[3,4]$. 
Cyclo-oxygenase and 5-lipoxygenase [5,6] exhibit anti-inflammatory [3,7] and anticancer [8,9] activities. Many synthesized compounds contain long-chain resonance and exhibit high antioxidant activity, such as 1, 2, and 3 [10-12] (Figure 1).

Figure 1. Di-tert-butyl-phenols with long-chain resonance as antioxidants.<smiles>CC(C)(C)c1cc(/C=C2\SC(=O)NC2=O)cc(C(C)(C)C)c1O</smiles>

1

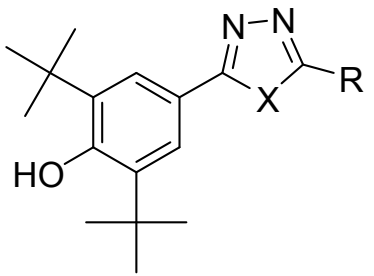

2

$$
\begin{aligned}
\mathrm{X}= & \mathrm{O}, \mathrm{S} \\
\mathrm{R}= & \mathrm{SH}, \mathrm{SMe}, \mathrm{SEt} \\
& \mathrm{SCH}_{2} \mathrm{COOH}, \\
& \mathrm{NH}_{2}, \mathrm{NHNH}_{2}
\end{aligned}
$$

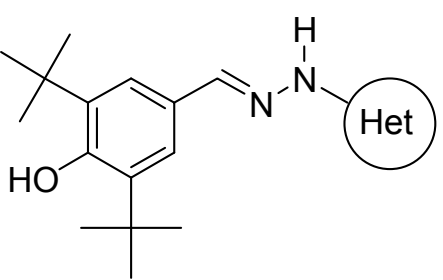

3

Het $=$ benzothiazol-2-yl, pyrazin-2-yl, pyridin-2-yl, pyrimidin-2-yl

Antioxidants donate protons to become a stable free radicals. This stability increases with the extent of delocalisation [13] and enhances antioxidant ability [14]. A number of 1,3,4-oxadiazole derivatives have exhibited various types of biological activity [15-17] and antioxidant ability $[18,19]$.

This paper describes the synthesis of eleven 2,6-di-tert-butyl-4-(5-aryl-1,3,4-oxadiazole-2-yl)phenols 5a-k (Scheme 1) and evaluates their antioxidant activity. These new oxadiazoles are designed to be effective antioxidants owing to their long-chain resonance. This study also investigates the effects of different substituents on the phenyl ring $\mathrm{C}$ at position 6 of the 1,3,4-oxadiazole. This structure is likely to possess superior antioxidant activity compared to the 2,6-di-tert-butyl phenol given the enhanced stability of the free radical of the 1,3,4-oxadiazole as a result of resonance. The inductive and resonance effects could have a major role in enhancing the scavenging ability of the compound. The antioxidant ability of these compounds were measured by means of FRAP and DPPH assays.

Scheme 1. Synthesis of 2,6-di-tert-butyl-4-(5-aryl-1,3,4-oxadiazol-2-yl)phenols.

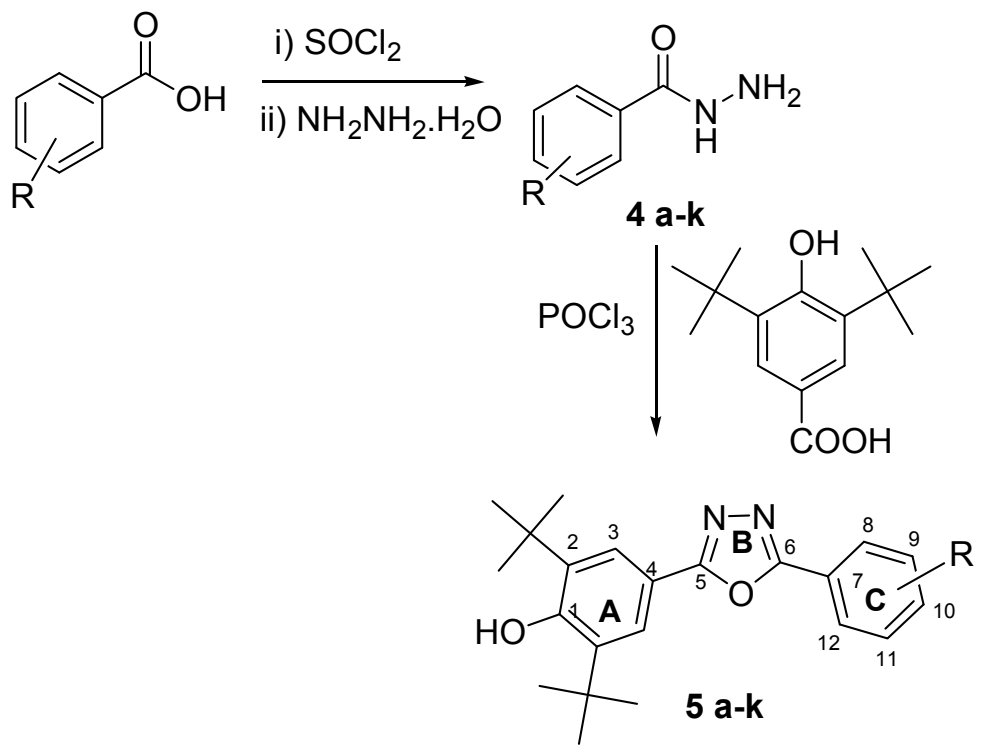




\section{Results and Discussion}

\section{Chemistry}

Eleven aromatic acids were converted to their corresponding aryl hydrazides $\mathbf{4 a}-\mathbf{k}$ by reacting the corresponding aromatic acids with thionyl chloride and then with hydrazine hydrate in dry benzene at $0{ }^{\circ} \mathrm{C}$. The aryl hydrazides were then reacted with 3,5-di-tert butyl 4-hydroxybenzoic acid in the presence of $\mathrm{POCl}_{3}$ as dehydrating agent to obtain new 2,6-di-tert-butyl-4-(5-aryl-1,3,4-oxadiazol-2-yl)phenols, as demonstrated in Scheme 1. Table 1 shows the aryl groups with the corresponding yields and HREIM data.

Table 1. Synthesized compounds, yields, molecular formulas (MFs) and HRMS data.

\begin{tabular}{|c|c|c|c|c|c|}
\hline No. & Compounds & Yield \% & MF & HREIMS found & HREIMS calc. \\
\hline $5 \mathbf{a}$ & & 76.1 & $\mathrm{C}_{23} \mathrm{H}_{28} \mathrm{~N}_{2} \mathrm{O}_{2}$ & 364.2147 & 364.2151 \\
\hline $5 b$ & & 76 & $\mathrm{C}_{23} \mathrm{H}_{28} \mathrm{~N}_{2} \mathrm{O}_{3}$ & 380.2095 & 380.2100 \\
\hline $5 c$ & & 84.2 & $\mathrm{C}_{24} \mathrm{H}_{30} \mathrm{~N}_{2} \mathrm{O}_{3}$ & 394.2249 & 394.2256 \\
\hline $5 d$ & & 73.6 & $\mathrm{C}_{22} \mathrm{H}_{25} \mathrm{BrN}_{2} \mathrm{O}_{2}$ & 428.1093 & 428.1099 \\
\hline $5 e$ & & 83.1 & $\mathrm{C}_{22} \mathrm{H}_{25} \mathrm{ClN}_{2} \mathrm{O}_{2}$ & 384.1597 & 384.1605 \\
\hline $5 f$ & & 70 & $\mathrm{C}_{22} \mathrm{H}_{26} \mathrm{~N}_{2} \mathrm{O}_{3}$ & 366.1938 & 366.1943 \\
\hline $5 g$ & & 80.3 & $\mathrm{C}_{22} \mathrm{H}_{24} \mathrm{Cl}_{2} \mathrm{~N}_{2} \mathrm{O}_{2}$ & 418.1219 & 418.1215 \\
\hline $5 \mathrm{~h}$ & & 74.5 & $\mathrm{C}_{22} \mathrm{H}_{24} \mathrm{Cl}_{2} \mathrm{~N}_{2} \mathrm{O}_{2}$ & 418.1210 & 418.1215 \\
\hline $5 i$ & & 59.9 & $\mathrm{C}_{24} \mathrm{H}_{30} \mathrm{~N}_{2} \mathrm{O}_{2}$ & 378.2301 & 378.2304 \\
\hline $5 \mathbf{j}$ & & 68.4 & $\mathrm{C}_{23} \mathrm{H}_{28} \mathrm{~N}_{2} \mathrm{O}_{2}$ & 364.2144 & 364.2151 \\
\hline $5 \mathbf{k}$ & & 81 & $\mathrm{C}_{22} \mathrm{H}_{25} \mathrm{ClN}_{2} \mathrm{O}_{2}$ & 384.1600 & 384.1605 \\
\hline
\end{tabular}


The structures of the compounds were established on the basis of their spectral data. The IR exhibited all the expected peaks, with the $\mathrm{OH}$ of the hindered phenol showing medium to strong peaks due to nonhydrogen bonding [20] at 3658-3525, $\mathrm{CH}_{\text {aliphatic }}$ ones at $2963-2947$, and the $\mathrm{C}=\mathrm{N}$ of the oxadiazole ring at $1624 \mathrm{~cm}^{-1}$ to $1608 \mathrm{~cm}^{-1}$. The ${ }^{1} \mathrm{H}$-NMR spectra displayed the di-tert butyl group with integration equal to $18 \mathrm{H}$, whose chemical shift ranged between $1.44 \mathrm{ppm}$ and $1.52 \mathrm{ppm}$. The $\mathrm{OH}$ of the hindered phenol appeared at $\delta 5.63$ to $\delta 5.69$. All aryl protons and their substituents appeared in the expected regions. The ${ }^{13} \mathrm{C}-\mathrm{NMR}$ spectra were consistent with the IR and ${ }^{1} \mathrm{H}-\mathrm{NMR}$ spectra and our expectations. The carbons of the oxadiazole ring appeared at $161 \mathrm{ppm}$ to $166 \mathrm{ppm}$, which represented $2(\mathrm{C}=\mathrm{N})$. HMBC was employed to distinguish between $\mathrm{C}_{5}$ and $\mathrm{C}_{6}$ through the long-range coupling $J_{3}$. The weak coupling $J_{2}$ was also determined (Figure 2), and it exhibited the most significant correlations for the aromatic area.

Figure 2. HMBC expansion region of $\mathbf{5 d}$.

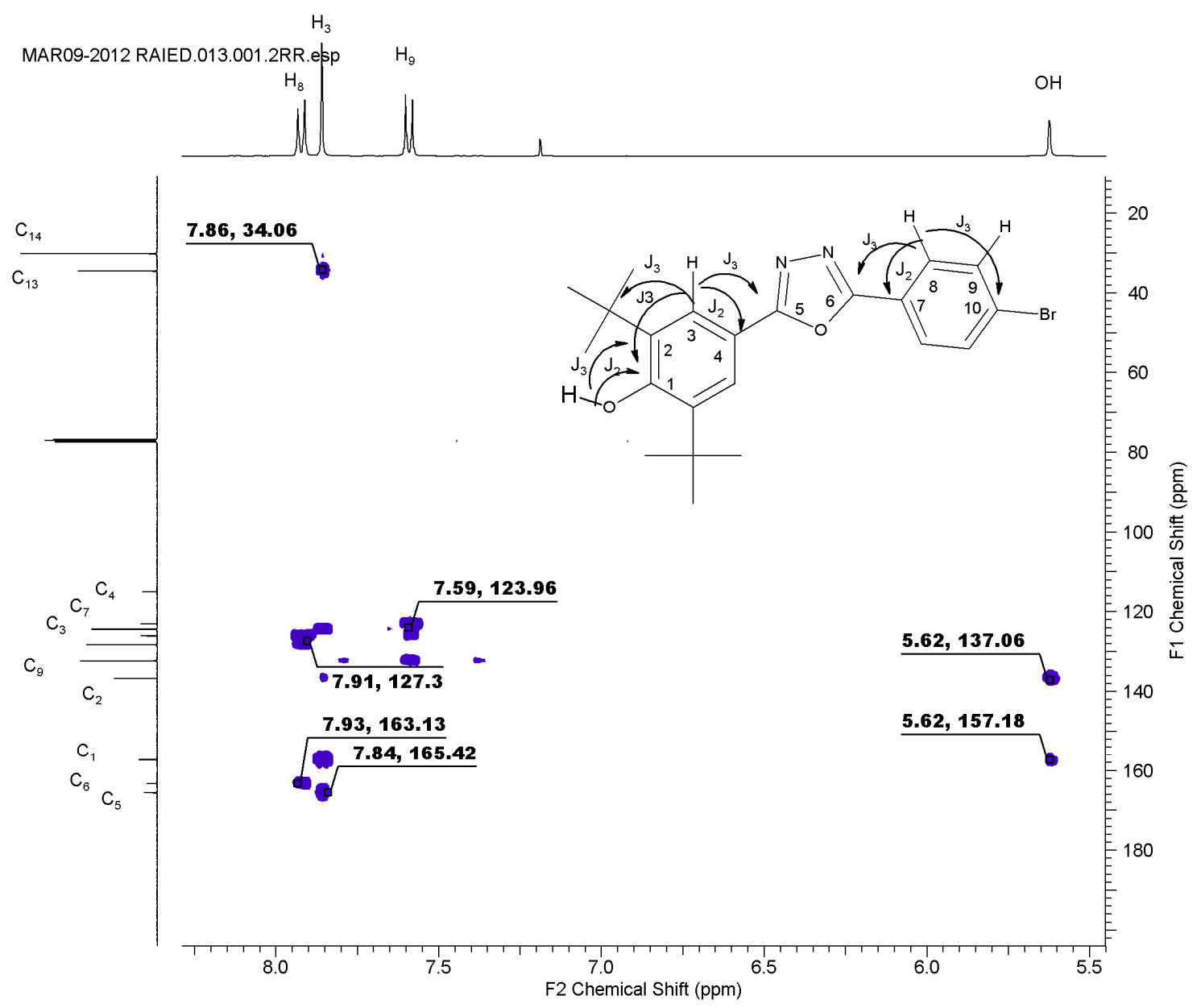

$\mathrm{H}_{3}$ exhibited correlations with $\mathrm{C}_{5}$ and $\mathrm{C}_{1}$ and weak correlations with $\mathrm{C}_{2}$ and $\mathrm{C}_{4} . \mathrm{H}_{8}$ exhibited a correlation with $\mathrm{C}_{6}$ and $\mathrm{C}_{10}$ owing to $J_{3}$, and with $\mathrm{C}_{7}$ and $\mathrm{C}_{9}$ owing to $J_{2}$. This spectrum confirmed that the $\mathrm{C}_{5}$ of the oxadiazole appeared at a lower field than $\mathrm{C}_{6}$. The HREIM values for all synthesized compounds were consistent with the calculated mass and the molecular formula. For more details, see the Experimental section.

The EIMs show the molecular ion $\mathrm{M}^{++}$for all compounds and the base peak $(100 \%)$ were either the same value of the molecular ion or the molecular ion minus methyl radical $\left[\mathrm{M}^{\cdot+}-{ }^{\circ} \mathrm{CH}_{3}\right]$. 
The fragmentations in EIMs confirm the proposed structures and the HREIMs confirmed the accurate mass and the molecular formula. The interesting fragmentation observed in the mass spectrum was the loss of isocyanic acid (HNCO). This fragmentation which strated from $\left[\mathrm{M}^{\circ+}+\mathrm{H}\right]$ was reported in literature [21-23]. The oxadiazoles loose HNCO but not phenol. However, in our case, losing HNCO started from molecular ion $\left(\mathrm{M}^{*+}\right)$ which was subsequently protonated. The loss of HNCO can be explained through the rearrangement of the molecular ion and migration. Scheme 2 describes the proposed mechanism of the elimination of isocyanic acid.

Scheme 2. Proposed pathways of HNCO loss.
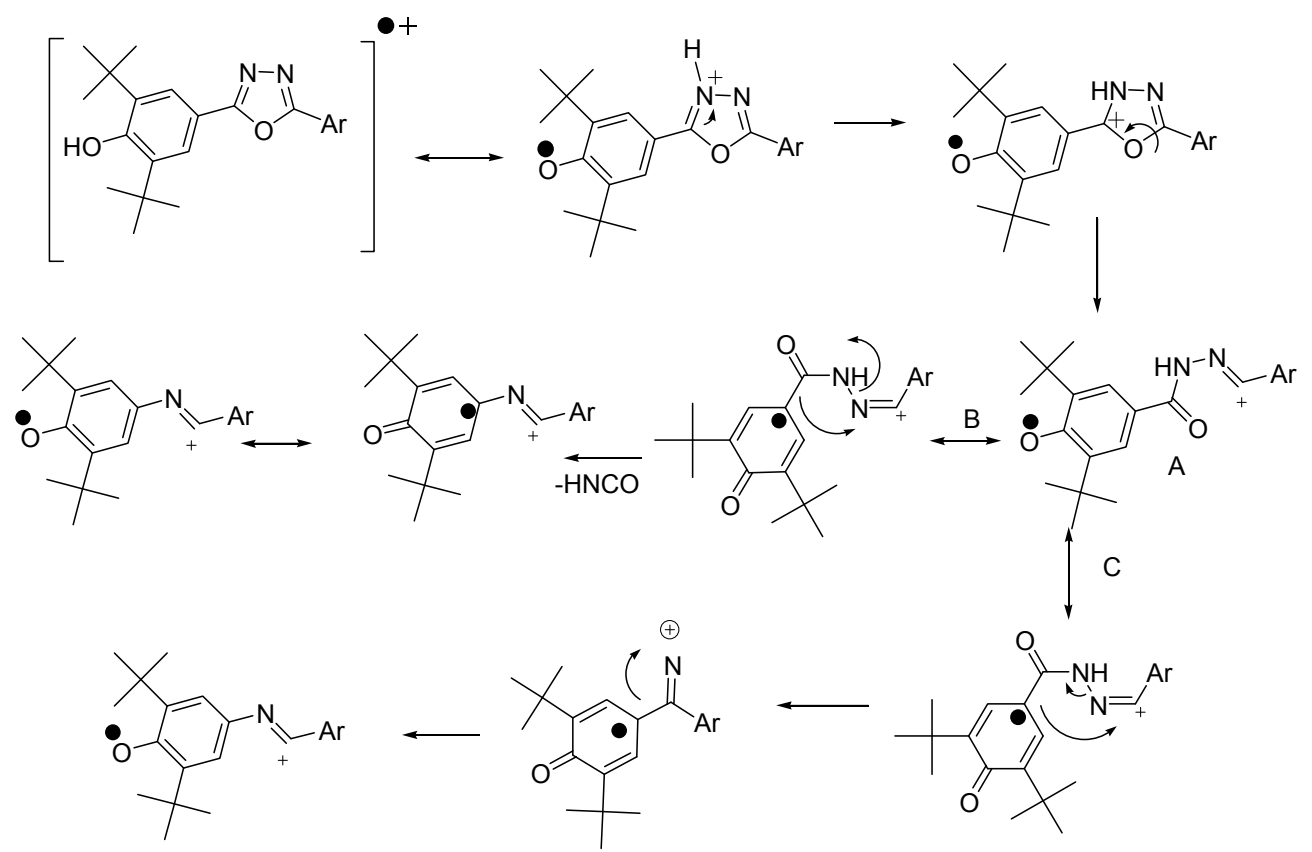

Two pathways were suggested for the radical migration, path (B) and (C). Both pathways, (B) and (C) have intermediate (A) as their starting point which is formed by intra fragmentation of the molecular ion and migration of 2,6-di-tert-butylphenol. Path $\mathrm{B}$ is similar to the mass fragmentation pathway proposed by Frański et al. [22]. Table 2 summarizes the value of the molecular ion, the base peak and value after losing $\mathrm{HNCO}$.

Table 2. Molecular ion found, calculated, base peak and the $m / z$ after losing HNCO.

\begin{tabular}{ccccc}
\hline $\mathbf{5}$ & $\mathbf{M}^{\mathbf{+}}$ Found & $\mathbf{M}^{\mathbf{+}}$ calculated & $\boldsymbol{m} / \mathbf{z}$ of base peak 100\% & $\mathbf{M}^{\mathbf{+}}$-HNCO \\
\hline $\mathbf{5 a}$ & 364.2 & 364.21 & 349.2 & 321.1 \\
$\mathbf{5 b}$ & 380.2 & 380.21 & 380.2 & 337.1 \\
$\mathbf{5 c}$ & 394.3 & 394.22 & 394.3 & 351.1 \\
$\mathbf{5 d}$ & 428.2 & 428.10 & 413.1 & 385.1 \\
$\mathbf{5 e}$ & 384.2 & 384.16 & 369.1 & 341.1 \\
$\mathbf{5 f}$ & 366.2 & 366.19 & 366.2 & 323.1 \\
$\mathbf{5 g}$ & 418.2 & 418.12 & 403.1 & 375.1 \\
$\mathbf{5 h}$ & 418.2 & 418.12 & 403.1 & 375.0 \\
$\mathbf{5 i}$ & 378.3 & 378.23 & 378.3 & 335.1 \\
$\mathbf{5 j}$ & 364.3 & 364.21 & 349.2 & 321.1 \\
$\mathbf{5 k}$ & 384.2 & 384.16 & 369.2 & 341.1 \\
\hline
\end{tabular}




\section{Antioxidant Assays}

\subsection{FRAP Assay}

The FRAP assay was performed according to the Benzie and Strain [24] method. The FRAP reagent was prepared by combining $300 \mathrm{mM}$ acetate buffer and $10 \mathrm{mM} \mathrm{2,4,6-tripyridyl-s-triazine}$ (TPTZ) solution in $40 \mathrm{mM} \mathrm{HCl}$ and $20 \mathrm{mM} \mathrm{FeCl}_{3} \cdot 6 \mathrm{H}_{2} \mathrm{O}$, in a ratio of 10:1:1. The FRAP reagent was incubated at $37{ }^{\circ} \mathrm{C}$ prior to use. Ten microliters of the sample was reconstituted in the carrier (solvent or ultrapure water) and mixed with $300 \mu \mathrm{L}$ of FRAP reagent. The mixture was incubated at $37^{\circ} \mathrm{C}$ for $4 \mathrm{~min}$ in a microplate reader. The absorbance of the complex was $593 \mathrm{~nm}$. The FRAP value can be calculated using the following equation [25]:

$\mathrm{FRAP}=[(0-4 \min \Delta \mathrm{A} 593 \mathrm{~nm}$ of test sample $) /(0-4 \min \Delta \mathrm{A} 593 \mathrm{~nm}$ of standard $)]$

$$
\times[\text { standard }](\mu \mathrm{M}) \times \mathrm{Y} \times 1000
$$

where $\mathrm{Y}$ is absorbance of the spectrophotometer.

\subsection{DPPH Assay}

The assay was performed as reported by Gerhauser et al. [26]. Five microliters of the sample (dissolved in ethanol) was added into $195 \mu \mathrm{L}$ of $100 \mu \mathrm{M}$ DPPH reagent in ethanol (96\%) and mixed in a 96-well plate. The intensity of the color was measured for $3 \mathrm{~h}$ at an interval of $20 \mathrm{~min}$ at $515 \mathrm{~nm}$. Ascorbic acid and BHT were used as reference.

\subsection{Antioxidant Activity}

Differences occurred between the structures of the synthesized compound in ring $\mathrm{C}$ owing to different substituent and positions, whereas rings A and B were the same. Various antioxidant abilities were exhibited in both assays based on the type of substituent and their position, which have important roles in enhancing or negating antioxidant ability. The inductive effects of the electron-donating group $+\mathrm{I}$ and electron-withdrawing group $(\mathrm{EWG})-\mathrm{I}$, the mesomeric effect (electron-releasing group $+\mathrm{M}$ or electron-withdrawing group $-\mathrm{M}$ ), and the resonance effect directly affected antioxidant ability. Compound 5f exhibited higher antioxidant capacity, with a FRAP value of 2207.25 (see Table 3). This result is consistent with the concept that the hydroxyl group enhances antioxidant ability [27-30]. The $+\mathrm{M}$ of the hydroxyl at the para position is more important than the $-\mathrm{I}$. Compound $\mathbf{5 j}$ exhibited excellent antioxidant ability (1538.9).

The FRAP value and the substituent followed the following sequence: 4-OH $>2$-Me $>2$,4-di-Me $>$ $4-\mathrm{Me}>4-\mathrm{OMe} \approx 4-\mathrm{OEt}>4-\mathrm{Cl}>2-\mathrm{Cl}>4-\mathrm{Br} \approx 3,4-\mathrm{di} \mathrm{Cl} \approx 3,5$-di $\mathrm{Cl}$. This sequence demonstrates that the electron-releasing group, which exerts mesomeric and inductive effects, enhances antioxidant ability, whereas the inductive-withdrawing group decreases antioxidant ability. The results show that the position of substituent also affects antioxidant ability, as illustrated in Figure 3. 
Table 3. Antioxidant activity of the synthesized oxadiazoles.

\begin{tabular}{|c|c|c|c|}
\hline Compound & FRAP $^{\text {a }}$ & DPPH Inhibition $\% \pm$ SD & $\mathrm{IC}_{50} \pm \mathrm{SEM}^{\mathrm{b}}(100 \mu \mathrm{g} / \mathrm{mL})$ \\
\hline $5 a$ & 648.3 & $76.02 \pm 0.059$ & $41.76 \pm 0.042$ \\
\hline $5 \mathbf{b}$ & 629.4 & $62.03 \pm 0.327$ & $50.69 \pm 0.181$ \\
\hline $5 c$ & 613.3 & $56.04 \pm 0.187$ & $54.60 \pm 0.469$ \\
\hline 5d & 302.2 & $30.85 \pm 0.166$ & $>100$ \\
\hline $5 e$ & 640.0 & $50.44 \pm 0.045$ & $99.2 \pm 0.032$ \\
\hline $5 f$ & 2207.2 & $89.05 \pm 0.024$ & $15.79 \pm 0.017$ \\
\hline $5 g$ & 322.8 & $30.35 \pm 0.038$ & $>100$ \\
\hline $5 \mathbf{h}$ & 212.8 & $29.26 \pm 0.041$ & $>100$ \\
\hline $5 \mathbf{i}$ & 987.2 & $79.22 \pm 0.037$ & $41.27 \pm 0.027$ \\
\hline $5 \mathbf{j}$ & 1538.9 & $87.21 \pm 0.084$ & $15.9 \pm 0.054$ \\
\hline $5 \mathbf{k}$ & 500.6 & $42.14 \pm 0.078$ & $>100$ \\
\hline BHT & 488.3 & $66.03 \pm 0.051$ & $79.84 \pm 0.036$ \\
\hline Gallic acid & 2421.1 & - & - \\
\hline Ascorbic acid & 848.9 & $90.65 \pm 0.122$ & $22.71 \pm 0.086$ \\
\hline Rutin & 445.0 & - & - \\
\hline Quercetin & 2090.6 & - & - \\
\hline Trolox & 779.4 & - & - \\
\hline
\end{tabular}

${ }^{\mathrm{a}}$ Standard deviation (SD) value in FRAP was between $0.01-0.16 ;{ }^{\mathrm{b}} \mathrm{SED}$ standard mean error and $\mathrm{IC}_{50}: 50 \%$ effective concentration.

Figure 3. FRAP assay for the synthesized 2,6-di-tert-butyl-4-(5-aryl-1,3,4-oxadiazol-2-yl)phenols.

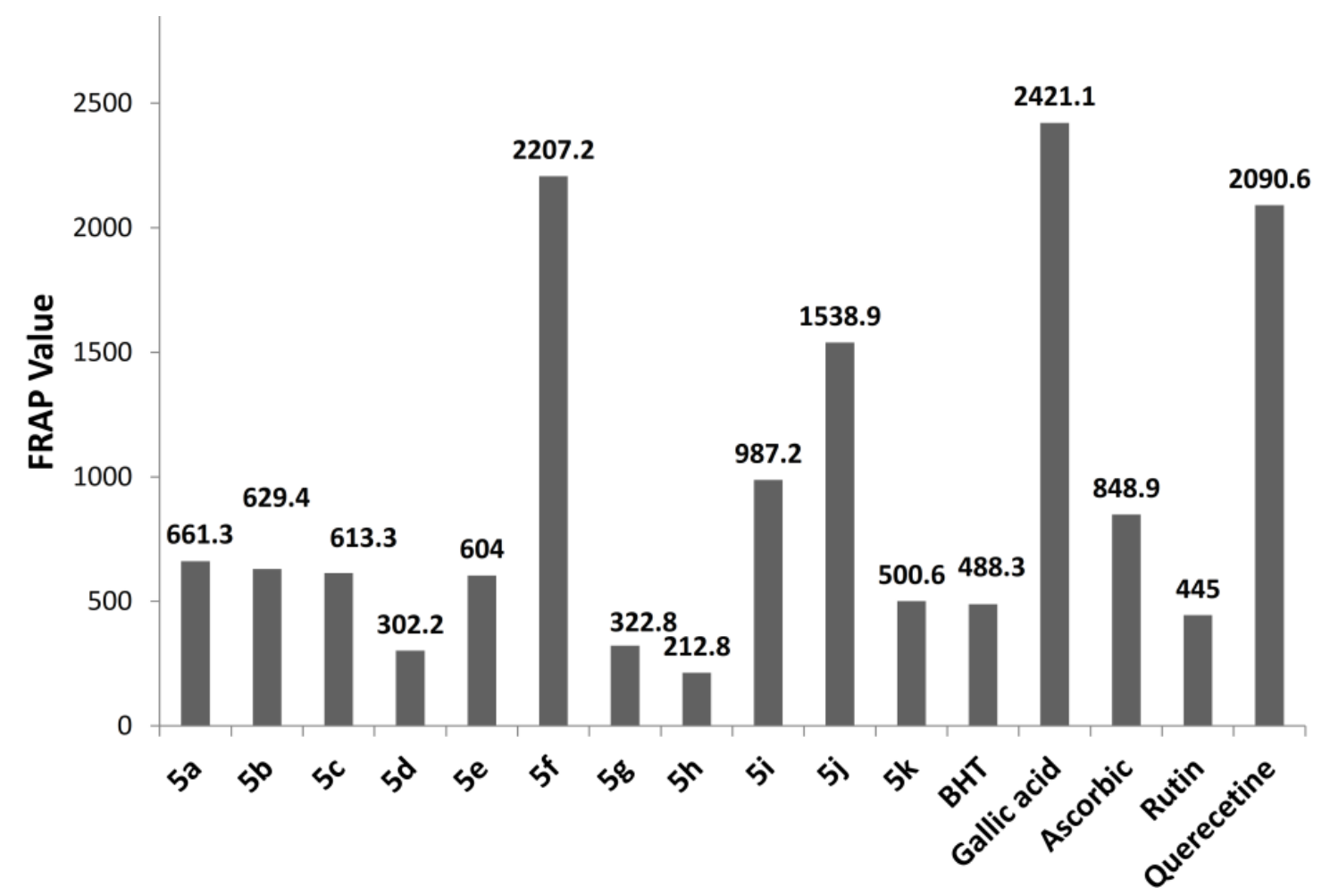

The methyl group at position 2 enhances the antioxidant ability more than that at position 4 , and exhibits higher antioxidant ability than 4-methoxy. However, the differences between 4-methoxy and 4-ethoxy were too small. The analogue with EWG in positions 2, 3, and 4, i.e., 4-Br, 4-Cl, 3,4-diCl, 
3,5-diCl reduced or negated antioxidant activity. The results may be explained by the fact that previously described analogues with EWG's, increase the bond dissociation energy. Another possibility is that they exhibit decreased antioxidant ability [31,32]. The DPPH results (Table 3) were compatible with, and possessed the same sequence, as the FRAP assay. However, all values for DPPH are on the whole lower than the values for the FRAP assay in comparison to ascorbic acid. For instance, in FRAP assay, $\mathbf{5 f}$ showed about twice the antioxidant ability of ascorbic acid, whereas in the DPPH assay, $\mathbf{5 f}$ exhibited similar antioxidant ability to ascorbic acid. This difference could be attributed to the different mechanisms for FRAP and DPPH. FRAP involves the single electron transfer mechanism, whereas DPPH assay depends on the H-atom transfer mechanism [33]. The steric hindrance between the synthesized compound and DPPH may account for the difference [34].

Compounds $\mathbf{5 f}$ and $\mathbf{5 j}$ exhibited lower $\mathrm{IC}_{50}$ values of 15.79 and $15.9 \mu \mathrm{g} / \mathrm{mL}$, respectively, compared to ascorbic acid. The $\mathrm{IC}_{50}$ of para substituted analogues with methyl, methoxy, and ethoxy were lower than that of BHT. By contrast, for electron withdrawing group at para, meta, and ortho, the analogues showed reduced antioxidant activity. All compounds were screened in terms of their free radical scavenging properties using five concentrations: $12.5,25,50,75$, and $100 \mu \mathrm{g} / \mathrm{mL}$. Both $\mathbf{5 f}$ and $\mathbf{5 j}$ exhibited significant antioxidant capability at low concentrations, as depicted in Figure 4.

Figure 4. DPPH inhibitions of $\mathbf{5} \mathbf{f}$ and $\mathbf{5 j}$ at different concentration.

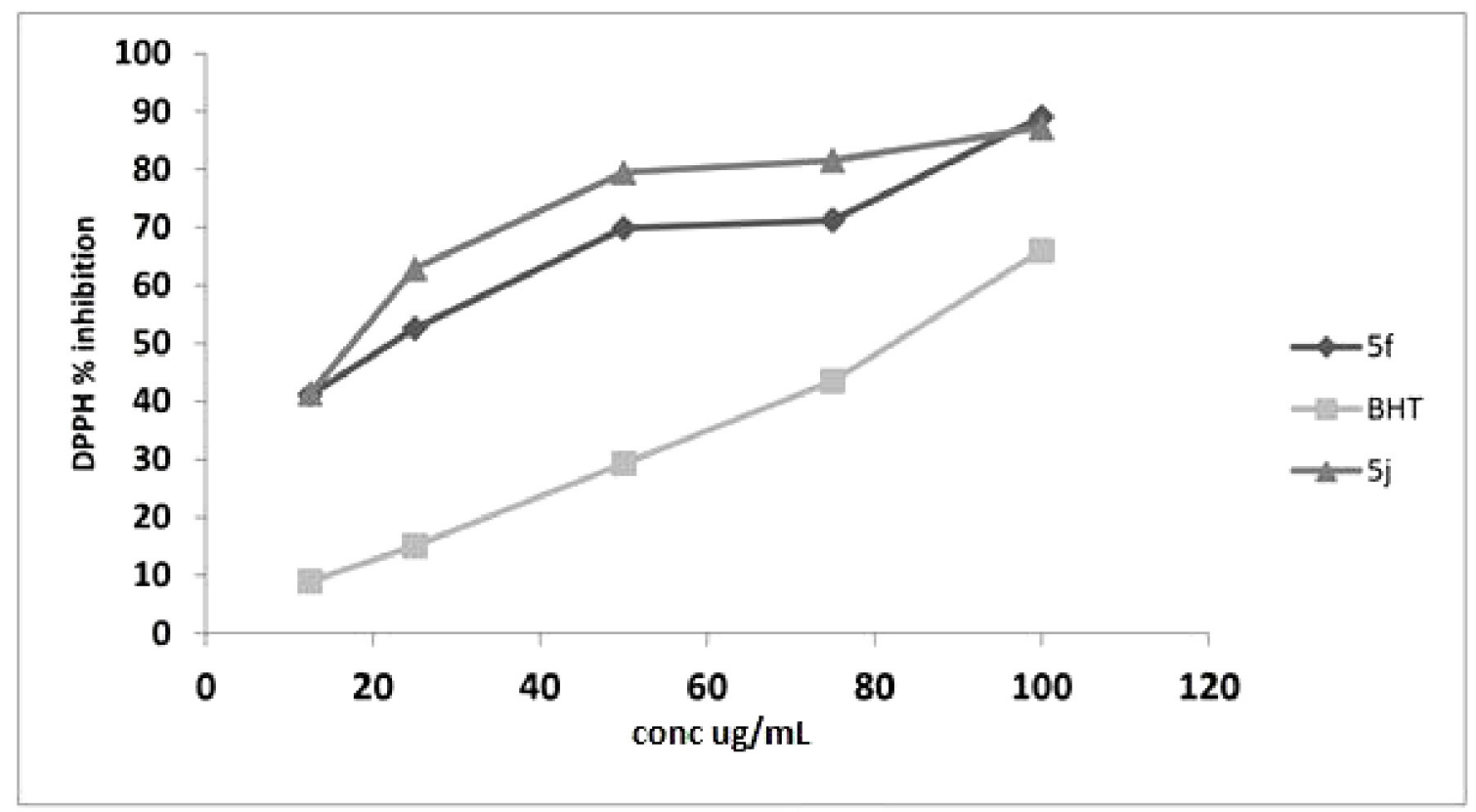

\section{Experimental}

\section{General Information}

The chemicals used for the synthesis were supplied by Sigma-Aldrich (Petaling Jaya, Selangor, Malaysia), Fisher (Shah Alam, Selangor, Malaysia), and Merck (Petaling Jaya, Selangor, Malaysia). The melting point was determined by open capillary tube method using an MEL-TEMP II apparatus and was uncorrected. The purity of the compounds was checked through thin layer chromatography (silica gel TLC) using Merck plates. The plates were visualized by mean of iodine vapors and UV 
light. The IR spectra were obtained using a PerkinElmer 400 Fourier transform infrared spectrometer. All NMR spectra were recorded on either a JEOL-ECA $400 \mathrm{MHz}$ or JEOL-Lambda $400 \mathrm{MHz}$ spectrometer. $\mathrm{CDCl}_{3}$ and DMSO- $d_{6}$ were used as solvents with TMS as the internal standard. Mass spectra were recorded using a TSQ7000 for HREI/MS (NUS Singapore). For UV spectroscopy, a Power Wave X340 (BIO-TEK Instruments, Inc., Winooski, VT, USA) was used to record the FRAP and DPPH assays.

General Synthesis of 2,6-Di-tert-butyl-4-(5-aryl-1,3,4-oxadiazol-2-yl)phenols

To a mixture of $(0.31 \mathrm{~g}, 1.24 \mathrm{mmol})$ of 3,5-di-tert-butyl-4-hydroxybenzoic acid and $1.24 \mathrm{mmole}$ aryl acid hydrazide in a $50 \mathrm{~mL}$ round bottom flask, $5 \mathrm{~mL}$ of phosphorus oxychloride was added in a few portions at room temperature. The mixture was refluxed for $3 \mathrm{~h}$ with stirring on water bath $80-90{ }^{\circ} \mathrm{C}$. After cooling, the mixture poured onto $100 \mathrm{~mL}$ crushed ice and stirred for $15 \mathrm{~min}$. Sodium bicarbonate was added in a few portions until the $\mathrm{pH}$ was around to $7-8$. The precipitate was filtered, washed with water and dried then purified either by column chromatography or by crystallization from suitable solvent.

2,6-Di-tert-butyl-4-[5-(4-methylphenyl)-1,3,4-oxadiazol-2-yl]phenol (5a). The product was recrystallized from chloroform-ethanol (1-1) to obtain white crystals. Yield $0.343 \mathrm{~g}(76.0 \%)$, m.p. $196-197{ }^{\circ} \mathrm{C}$, IR $\left(\mathrm{KBr}, v_{\max } / \mathrm{cm}^{-1}\right)$ : $3658(\mathrm{OH}), 3011\left(\mathrm{CH}_{\text {aromatic }}\right), 2962-2947\left(\mathrm{CH}_{\text {aliphatic }}\right), 1610(\mathrm{C}=\mathrm{N}), 1585,1498(\mathrm{C}=\mathrm{C})$, 1219 (C-O), ${ }^{1} \mathrm{H}-\mathrm{NMR}\left(\mathrm{CDCl}_{3}, 400 \mathrm{MHz}, \mathrm{ppm}\right): 1.51$ (s, 18H, $\mathrm{H}_{14}, 2 \times t$-Bu), 2.42 (s, 3H, p-CH - $_{3}$-ph), 5.67 (s, 1H, OH), $7.31\left(\mathrm{~d}, 2 \mathrm{H}, J=8.28 \mathrm{~Hz}, \mathrm{H}_{9}, \mathrm{H}_{11}\right), 7.94\left(\mathrm{~s}, 2 \mathrm{H}, \mathrm{H}_{3}\right), 8.01\left(\mathrm{~d}, 2 \mathrm{H}, J=8.28 \mathrm{~Hz}, \mathrm{H}_{8}, \mathrm{H}_{12}\right)$, ${ }^{13} \mathrm{C}-\mathrm{NMR}\left(\mathrm{CDCl}_{3}, 100 \mathrm{MHz}, \mathrm{ppm}\right): 21.73\left(p-\mathrm{CH}_{3} \mathrm{Ph}\right), 30.25\left(6 \mathrm{C}, \mathrm{C}_{14}, 2 \times \mathrm{C}\left(\underline{\mathrm{CH}}_{3}\right)_{3}\right), 34.56\left(2 \mathrm{C}, \mathrm{C}_{13}\right.$, $\left.2 \times \underline{\mathrm{C}}\left(\mathrm{CH}_{3}\right)_{3}\right), 115.43\left(\mathrm{C}_{4}\right), 121.52\left(\mathrm{C}_{7}\right), 124.35\left(\mathrm{C}_{3}\right), 126.87\left(2 \mathrm{C}, \mathrm{C}_{8} \& \mathrm{C}_{12}\right), 129.77\left(2 \mathrm{C}, \mathrm{C}_{9} \& \mathrm{C}_{11}\right)$, $136.81\left(\mathrm{C}_{2}\right), 141.99\left(\mathrm{C}_{10}\right), 157.12\left(\mathrm{C}_{1}\right), 164.22 \& 165.21\left(\mathrm{C}_{5} \& \mathrm{C}_{6}\right)$. HREIMs, $m / z=364.2147\left[\mathrm{M}^{*+}\right]$ (calc. for $\mathrm{C}_{23} \mathrm{H}_{28} \mathrm{O}_{2} \mathrm{~N}_{2}, 364.2151$ ).

2,6-Di-tert-butyl-4-[5-(4-methox yphenyl)-1,3,4-oxadiazol-2-yl]phenol (5b). The solid product was recrystallized from ethyl acetate to yield white crystals. Yield $0.346 \mathrm{~g}(73 \%)$, m.p. $179-181{ }^{\circ} \mathrm{C}$, IR $\left(\mathrm{KBr}, v_{\max } / \mathrm{cm}^{-1}\right): 3625\left(\mathrm{OH}_{\text {phenol }}\right), 3006\left(\mathrm{CH}_{\text {aromatic }}\right), 2955\left(\mathrm{CH}_{\text {aliphatic }}\right), 1611(\mathrm{C}=\mathrm{N}), 1585,1495(\mathrm{C}=\mathrm{C})$,

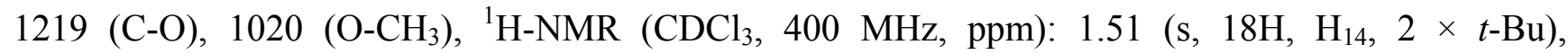
$3.89\left(\mathrm{~s}, 3 \mathrm{H}, \mathrm{OCH}_{3}\right), 5.63(\mathrm{~s}, 1 \mathrm{H}, \mathrm{OH}), 7.03\left(\mathrm{~d}, 2 \mathrm{H}, J=9.04 \mathrm{~Hz}, \mathrm{H}_{9}, \mathrm{H}_{11}\right), 7.92\left(\mathrm{~s}, 2 \mathrm{H}, \mathrm{H}_{3}\right), 8.06(\mathrm{~d}, 2 \mathrm{H}$, $\left.J=8.56 \mathrm{~Hz}, \mathrm{H}_{8}, \mathrm{H}_{12}\right),{ }^{13} \mathrm{C}-\mathrm{NMR}\left(\mathrm{CDCl}_{3}, 100 \mathrm{MHz}, \mathrm{ppm}\right): 30.13\left(6 \mathrm{C}, \mathrm{C}_{14}, 2 \times \mathrm{C}\left(\underline{\mathrm{CH}}_{3}\right)_{3}\right), 34.45(2 \mathrm{C}$, $\left.\mathrm{C}_{13}, 2 \times \underline{\mathrm{C}}\left(\mathrm{CH}_{3}\right)_{3}\right), 55.44\left(\mathrm{OCH}_{3}\right), 114.40\left(2 \mathrm{C}, \mathrm{C}_{8} \& \mathrm{C}_{12}\right), 115.37\left(\mathrm{C}_{4}\right), 116.72\left(\mathrm{C}_{7}\right), 124.19\left(\mathrm{C}_{3}\right)$, $128.58\left(2 \mathrm{C}, \mathrm{C}_{9} \& \mathrm{C}_{11}\right), 136.68\left(\mathrm{C}_{2}\right), 156.95\left(\mathrm{C}_{1}\right), 162.11\left(\mathrm{C}_{10}\right), 163.89 \& 164.75\left(\mathrm{C}_{6} \& \mathrm{C}_{5}\right)$. HREIMs, $m / z=380.2095\left[\mathrm{M}^{*+}\right]$ (calc. for $\mathrm{C}_{23} \mathrm{H}_{28} \mathrm{O}_{3} \mathrm{~N}_{2}, 380.2100$ ).

2,6-Di-tert-butyl-4-[5-(4-ethoxyphenyl)-1,3,4-oxadiazol-2-yl]phenol (5c). The crude solid was recrystallized from ethyl acetate-methanol (1:1) to give a white amorphous solid. Yield $0.371 \mathrm{~g} \mathrm{(76 \% ),}$ m.p. $176-178^{\circ} \mathrm{C}$, IR $\left(\mathrm{KBr}, v_{\max } / \mathrm{cm}^{-1}\right), 3628\left(\mathrm{OH}_{\text {phenol }}\right), 3009\left(\mathrm{CH}_{\text {aromatic }}\right), 2957\left(\mathrm{CH}_{\text {aliphatic }}\right), 1611(\mathrm{C}=\mathrm{N})$, 1543, $1495(\mathrm{C}=\mathrm{C}), 1221(\mathrm{C}-\mathrm{O}), 1111\left(\mathrm{O}-\mathrm{CH}_{2}\right),{ }^{1} \mathrm{H}-\mathrm{NMR}\left(\mathrm{CDCl}_{3}, 400 \mathrm{MHz}, \mathrm{ppm}\right): 1.46$ (t, 3H, $\left.J=7.32 \mathrm{~Hz}, \mathrm{OCH}_{2} \underline{\mathrm{CH}}_{3}\right), 1.51\left(\mathrm{~s}, 18 \mathrm{H}, \mathrm{H}_{14}, 2 \times t-\mathrm{Bu}\right), 4.11\left(\mathrm{q}, 2 \mathrm{H}, J=8 \mathrm{~Hz}, \mathrm{OCH}_{2}\right), 5.64(\mathrm{~s}, 1 \mathrm{H}, \mathrm{OH})$, $7.1\left(\mathrm{~d}, 2 \mathrm{H}, J=8.8 \mathrm{~Hz}, \mathrm{H}_{9} \& \mathrm{H}_{11}\right), 7.92\left(\mathrm{~s}, 1 \mathrm{H}, \mathrm{H}_{3}\right), 8.05\left(\mathrm{~d}, 2 \mathrm{H}, J=8.04 \mathrm{~Hz}, \mathrm{H}_{8} \& \mathrm{H}_{12}\right),{ }^{13} \mathrm{C}-\mathrm{NMR}$ $\left(\mathrm{CDCl}_{3}, 100 \mathrm{MHz}, \mathrm{ppm}\right): 14.71\left(\mathrm{OCH}_{2} \underline{\mathrm{CH}}_{3}\right), 30.17\left(6 \mathrm{C}, \mathrm{C}_{14}, 2 \times \mathrm{C}\left(\underline{\mathrm{CH}}_{3}\right)_{3}\right), 34.48\left(2 \mathrm{C}, \mathrm{C}_{13}, 2 \times \underline{\mathrm{C}}\left(\mathrm{CH}_{3}\right)_{3}\right)$, 
$63.73\left(\underline{\mathrm{OCH}}_{2}\right), 114.91\left(2 \mathrm{C}, \mathrm{C}_{8} \& \mathrm{C}_{12}\right), 115.50\left(\mathrm{C}_{4}\right), 116.60\left(\mathrm{C}_{7}\right), 124.18\left(\mathrm{C}_{3}\right), 128.57\left(2 \mathrm{C}, \mathrm{C}_{9} \& \mathrm{C}_{11}\right)$, $136.69\left(\mathrm{C}_{2}\right), 156.93\left(\mathrm{C}_{1}\right), 161.52\left(\mathrm{C}_{10}\right), 164.00 \& 164.90\left(\mathrm{C}_{6} \& \mathrm{C}_{5}\right)$. HREIMs, $m / z=394.2249\left[\mathrm{M}^{*+}\right]$ (calc. for $\mathrm{C}_{24} \mathrm{H}_{30} \mathrm{O}_{3} \mathrm{~N}_{2}, 394.2256$ ).

4-(5-(4-Bromophenyl)-1,3,4-oxadiazol-2-yl)-2,6-di-tert-butylphenol (5d). The crude product was

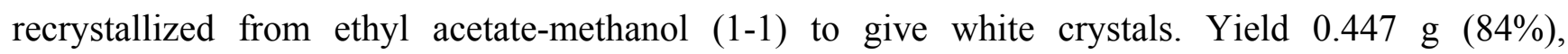
m.p. $168-170{ }^{\circ} \mathrm{C}$, IR $\left(\mathrm{KBr}, v_{\max } / \mathrm{cm}^{-1}\right): 3525\left(\mathrm{OH}_{\text {phenol }}\right), 3005\left(\mathrm{CH}_{\text {aromatic }}\right), 2953\left(\mathrm{CH}_{\text {aliphatic }}\right), 1602(\mathrm{C}=\mathrm{N})$, 1543, $1495(\mathrm{C}=\mathrm{C}), 1244(\mathrm{C}-\mathrm{O}),{ }^{1} \mathrm{H}-\mathrm{NMR}\left(\mathrm{CDCl}_{3}, 400 \mathrm{MHz}, \mathrm{ppm}\right): 1.51\left(\mathrm{~s}, 18 \mathrm{H}, \mathrm{H}_{14}, 2 \times t\right.$-Bu), $5.66(\mathrm{~s}, 1 \mathrm{H}, \mathrm{OH}), 7.67$ (d, 2H, $\left.J=8.42 \mathrm{~Hz}, \mathrm{H}_{9} \& \mathrm{H}_{11}\right), 7.92\left(\mathrm{~s}, 2 \mathrm{H}, \mathrm{H}_{3}\right), 7.9$ (d, 2H, J=8.54 Hz, $\mathrm{H}_{8} \& \mathrm{H}_{12}$ ), ${ }^{13} \mathrm{C}-\mathrm{NMR}\left(\mathrm{CDCl}_{3}, 100 \mathrm{MHz}, \mathrm{ppm}\right): 30.23\left(6 \mathrm{C}, \mathrm{C}_{14}, 2 \times \mathrm{C}\left(\underline{\mathrm{CH}}_{3}\right)_{3}\right), 34.56\left(2 \mathrm{C}, \mathrm{C}_{13}, 2 \times \underline{\mathrm{C}}\left(\mathrm{CH}_{3}\right)_{3}\right)$, $115.12\left(\mathrm{C}_{4}\right), 123.22\left(\mathrm{C}_{7}\right), 124.43\left(\mathrm{C}_{3}\right), 126.1\left(2 \mathrm{C}, \mathrm{C}_{8} \& \mathrm{C}_{12}\right), 128.31\left(2 \mathrm{C}, \mathrm{C}_{9} \& \mathrm{C}_{11}\right), 132.41\left(\mathrm{C}_{10}\right)$, $136.87\left(\mathrm{C}_{2}\right), 157.33(\mathrm{C} 1), 163.37 \& 165.66\left(\mathrm{C}_{5} \& \mathrm{C}_{6}\right) \mathrm{ppm}$. HREIMs $m / z=428.1093\left[\mathrm{M}^{*+}\right]$ (calc. for $\left.\mathrm{C}_{22} \mathrm{H}_{25} \mathrm{O}_{2} \mathrm{~N}_{2} \mathrm{Br}, 428.1099\right)$.

4-(5-(4-Chlorophenyl)-1,3,4-oxadiazol-2-yl)-2,6-di-tert-butylphenol (5e). The crude material was recrystallized from ethyl acetate-methanol (1:1) to obtain a white solid. Yield $0.396 \mathrm{~g}(83 \%)$, m.p. $162-164{ }^{\circ} \mathrm{C}$, IR $\left(\mathrm{KBr}, v_{\max } / \mathrm{cm}^{-1}\right): 3583\left(\mathrm{OH}_{\text {phenol }}\right), 3004\left(\mathrm{CH}_{\text {aromatic }}\right), 2959\left(\mathrm{CH}_{\text {aliphatic }}\right), 1607(\mathrm{C}=\mathrm{N})$, 1571, 1540 (C=C), 1239 (C-O). ${ }^{1} \mathrm{H}-\mathrm{NMR}\left(\mathrm{CDCl}_{3}-400 \mathrm{MHz}, \mathrm{ppm}\right): 1.51$ (s, 18H, $\mathrm{H}_{14}, 2 \times t$-Bu), 5.67 (s, $1 \mathrm{H}, \mathrm{OH}), 7.51$ (d, 2H, $\left.J=8.52 \mathrm{~Hz}, \mathrm{H}_{9} \& \mathrm{H}_{11}\right), 7.93\left(\mathrm{~s}, 2 \mathrm{H}, \mathrm{H}_{3}\right), 8.07$ (d, 2H, J=8.52 Hz, $\left.\mathrm{H}_{8} \& \mathrm{H}_{12}\right)$, ${ }^{13} \mathrm{C}-\mathrm{NMR}\left(\mathrm{CDCl}_{3}, 100 \mathrm{MHz}, \mathrm{ppm}\right): 30.23\left(6 \mathrm{C}, \mathrm{C}_{14}, 2 \times \mathrm{C}\left(\underline{\mathrm{CH}}_{3}\right)_{3}\right), 34.56\left(2 \mathrm{C}, \mathrm{C}_{13}, 2 \times \underline{\mathrm{C}}\left(\mathrm{CH}_{3}\right)_{3}\right)$, $115\left(\mathrm{C}_{4}\right), 122.78\left(\mathrm{C}_{7}\right), 124.27\left(\mathrm{C}_{3}\right), 129.46\left(2 \mathrm{C}, \mathrm{C}_{9} \& \mathrm{C}_{11}\right) 128.18\left(2 \mathrm{C}, \mathrm{C}_{8} \& \mathrm{C}_{12}\right), 136.87\left(\mathrm{C}_{2}\right)$, $137.71\left(\mathrm{C}_{10}\right), 157.32\left(\mathrm{C}_{1}\right), 163.29 \& 165.64\left(\mathrm{C}_{5} \& \mathrm{C}_{6}\right)$. HREIMs $m / z=384.1597\left[\mathrm{M}^{*+}\right]$ (calc. for $\left.\mathrm{C}_{22} \mathrm{H}_{25} \mathrm{O}_{2} \mathrm{~N}_{2} \mathrm{Cl}, 384.1605\right)$.

2,6-Di-tert-butyl-4-(5-(4-hydroxyphenyl)-1,3,4-oxadiazol-2-yl)phenol (5f). The crude mixture was purified by column chromatography using (6:1) hexane ethyl acetate as eluent to give a white amorphous solid. Yield $0.318 \mathrm{~g}(70 \%)$, m.p. $144-146{ }^{\circ} \mathrm{C}$, IR $\left(\mathrm{KBr}, v_{\max } / \mathrm{cm}^{-1}\right): 3617\left(\mathrm{OH}_{\text {phenol }}\right), 2958\left(\mathrm{CH}_{\text {aliphatic }}\right)$, $1609(\mathrm{C}=\mathrm{N}), 1546,1506(\mathrm{C}=\mathrm{C}), 1250(\mathrm{C}-\mathrm{O}),{ }^{1} \mathrm{H}-\mathrm{NMR}\left(\mathrm{CDCl}_{3}, 400 \mathrm{MHz}, \mathrm{ppm}\right): 1.51\left(\mathrm{~s}, 18 \mathrm{H}, \mathrm{H}_{14}\right.$, $2 \times t-\mathrm{Bu}), 5.65(\mathrm{~s}, 1 \mathrm{H}, \mathrm{OH}), 6.70(\mathrm{bs}, 1 \mathrm{H}, \mathrm{OH}), 7.01\left(\mathrm{~d}, 2 \mathrm{H}, J=8.76 \mathrm{~Hz}, \mathrm{H}_{9} \& \mathrm{H}_{11}\right), 7.92\left(\mathrm{~s}, 1 \mathrm{H}, \mathrm{H}_{3}\right)$, $\left.8.01\left(\mathrm{~d}, 2 \mathrm{H}, J=8.8 \mathrm{~Hz}, \mathrm{H}_{8} \& \mathrm{H}_{12}\right),{ }^{13} \mathrm{C}-\mathrm{NMR}\left(\mathrm{CDCl}_{3}, 100 \mathrm{MHz}, \mathrm{ppm}\right): 31.06\left(6 \mathrm{C}, \mathrm{C}_{14}, 2 \times \mathrm{C}_{\left(\mathrm{CH}_{3}\right.}\right)_{3}\right)$, $34.56\left(2 \mathrm{C}, \mathrm{C}_{13}, 2 \times \underline{\mathrm{C}}\left(\mathrm{CH}_{3}\right)_{3}\right), 115.27\left(\mathrm{C}_{4}\right), 115.58\left(\mathrm{C}_{7}\right), 116.40\left(2 \mathrm{C}, \mathrm{C}_{8} \& \mathrm{C}_{12}\right), 124.37\left(\mathrm{C}_{3}\right)$, $128.97\left(2 \mathrm{C}, \mathrm{C}_{9} \& \mathrm{C}_{11}\right), 136.85\left(\mathrm{C}_{2}\right), 157.24\left(\mathrm{C}_{1}\right) 159.83\left(\mathrm{C}_{10}\right), 164.33 \& 165.05\left(\mathrm{C}_{5} \& \mathrm{C}_{6}\right)$. HREIMs $m / z=366.1938\left[\mathrm{M}^{\bullet+}\right]$ (calc. for $\mathrm{C}_{22} \mathrm{H}_{26} \mathrm{O}_{3} \mathrm{~N}_{2}, 366.1943$ ).

2,6-Di-tert-butyl-4-(5-(3,4-dichlorophenyl)-1,3,4-oxadiazol-2-yl)phenol (5g). The crude product was recrystallized from benzene to give a white solid. Yield $0.416 \mathrm{~g}(80 \%)$, m.p. $222-224{ }^{\circ} \mathrm{C}$, IR $(\mathrm{KBr}$, $\left.v_{\text {max }} / \mathrm{cm}^{-1}\right): 3580\left(\mathrm{OH}_{\text {phenol }}\right), 3003\left(\mathrm{CH}_{\text {aromatic }}\right), 2952\left(\mathrm{CH}_{\text {aliphatic }}\right), 1606(\mathrm{C}=\mathrm{N}), 1546,1462(\mathrm{C}=\mathrm{C})$, 1239 (C-O). ${ }^{1} \mathrm{H}-\mathrm{NMR}\left(\mathrm{CDCl}_{3}, 400 \mathrm{MHz}, \mathrm{ppm}\right): 1.44$ (s, 18H, $\left.\mathrm{H}_{14}, 2 \times t-\mathrm{Bu}\right), 5.67(\mathrm{~s}, 1 \mathrm{H}, \mathrm{OH})$, $7.59\left(\mathrm{~d}, 2 \mathrm{H}, J=8.52 \mathrm{~Hz}, \mathrm{H}_{11}\right), 7.91-7.95\left(\mathrm{~m}, 3 \mathrm{H}, \mathrm{H}_{12} \& \mathrm{H}_{3^{\prime}}\right), 8.19\left(\mathrm{~d}, J=2.2 \mathrm{~Hz}, 1 \mathrm{H}, \mathrm{H}_{8}\right),{ }^{13} \mathrm{C}-\mathrm{NMR}$ $\left(\mathrm{CDCl}_{3}, 100 \mathrm{MHz}, \mathrm{ppm}\right): 30.23\left(6 \mathrm{C}, \mathrm{C}_{14}, 2 \times \mathrm{C}\left(\underline{\mathrm{CH}}_{3}\right)_{3}\right), 34.57\left(2 \mathrm{C}, \mathrm{C}_{13}, 2 \times \underline{\mathrm{C}}\left(\mathrm{CH}_{3}\right)_{3}\right), 114.89\left(\mathrm{C}_{4}\right)$, $124.11\left(\mathrm{C}_{7}\right), 124.51\left(\mathrm{C}_{3}\right), 125.95\left(\mathrm{C}_{12}\right), 128.53\left(\mathrm{C}_{11}\right), 131.28\left(\mathrm{C}_{8}\right), 133.68\left(\mathrm{C}_{9}\right), 135.89\left(\mathrm{C}_{10}\right)$, $136.94\left(\mathrm{C}_{2}\right), 157.50\left(\mathrm{C}_{1}\right), 162.3 \& 165.94\left(\mathrm{C}_{5} \& \mathrm{C}_{6}\right)$. HREIMs $m / z=418.1219\left[\mathrm{M}^{\circ+}\right]$ (calc. for $\mathrm{C}_{22} \mathrm{H}_{24} \mathrm{O}_{2} \mathrm{~N}_{2} \mathrm{Cl}_{2}, 418.1215$ ). 
2,6-Di-tert-butyl-4-(5-(3,5-dichlorophenyl)-1,3,4-oxadiazol-2-yl)phenol (5h). The crude product was purified by recrystallized from acetonitrile to afford a white amorphous solid. Yield $0.386 \mathrm{~g}$ (74\%), m.p. $195-197^{\circ} \mathrm{C}$, IR $\left(\mathrm{KBr}, v_{\max } / \mathrm{cm}^{-1}\right): 3600\left(\mathrm{OH}_{\text {phenol }}\right), 3007\left(\mathrm{CH}_{\text {aromatic }}\right), 2961\left(\mathrm{CH}_{\text {aliphatic }}\right), 1606(\mathrm{C}=\mathrm{N})$, 1574, $1550(\mathrm{C}=\mathrm{C}), 1240(\mathrm{C}-\mathrm{O}),{ }^{1} \mathrm{H}-\mathrm{NMR}\left(\mathrm{CDCl}_{3}, 400 \mathrm{MHz}, \mathrm{ppm}\right): 1.52\left(\mathrm{~s}, 18 \mathrm{H}, \mathrm{H}_{14}, 2 \times t\right.$-Bu), $5.69(\mathrm{~s}, 1 \mathrm{H}, \mathrm{OH}), 7.51\left(\mathrm{t}, 1 \mathrm{H}, J=1.24 \mathrm{~Hz}, \mathrm{H}_{10}\right), 7.93\left(\mathrm{~s}, 2 \mathrm{H}, \mathrm{H}_{3}\right), 8.01\left(\mathrm{t}, 2 \mathrm{H}, J=1.72 \mathrm{~Hz}, \mathrm{H}_{8} \& \mathrm{H}_{12}\right)$, ${ }^{13} \mathrm{C}-\mathrm{NMR}\left(\mathrm{CDCl}_{3}, 100 \mathrm{MHz}, \mathrm{ppm}\right): 30.39\left(6 \mathrm{C}, \mathrm{C}_{14}, 2 \times \mathrm{C}\left(\underline{\mathrm{CH}}_{3}\right)_{3}\right), 34.50\left(2 \mathrm{C}, \mathrm{C}_{13}, 2 \times \underline{\mathrm{C}}\left(\mathrm{CH}_{3}\right)_{3}\right)$, $114.73\left(\mathrm{C}_{4}\right), 124.48\left(\mathrm{C}_{3}\right), 125.02\left(2 \mathrm{C}, \mathrm{C}_{8} \& \mathrm{C}_{12}\right), 126.87\left(\mathrm{C}_{7}\right), 131.24\left(\mathrm{C}_{10}\right), 135.92\left(\mathrm{C}_{9} \& \mathrm{C}_{11}\right)$, $136.93\left(\mathrm{C}_{2}\right), 157.50\left(\mathrm{C}_{1}\right), 161.877\left(\mathrm{C}_{5}\right), 166.05(\mathrm{C} 6)$. HREIMs $m / z=418.1210\left[\mathrm{M}^{\circ+}\right]$ (calc. for $\left.\mathrm{C}_{22} \mathrm{H}_{24} \mathrm{O}_{2} \mathrm{~N}_{2} \mathrm{Cl}_{2}, 418.1215\right)$.

2,6-Di-tert-butyl-4-(5-(2,4-dimethylphenyl)-1,3,4-oxadiazol-2-yl)phenol (5i). The crude product was purified by recrystallized from toluene to give white crystalline needles. Yield $0.28 \mathrm{~g}(60 \%)$, m.p. $170-172{ }^{\circ} \mathrm{C}$. IR (KBr, $\left.v_{\max } / \mathrm{cm}^{-1}\right): 3587\left(\mathrm{OH}_{\text {phenol }}\right), 2957\left(\mathrm{CH}_{\text {aliphatic }}\right), 1614(\mathrm{C}=\mathrm{N}), 1550,1536(\mathrm{C}=\mathrm{C}), 1238(\mathrm{C}-\mathrm{O})$, ${ }^{1} \mathrm{H}-\mathrm{NMR}\left(\mathrm{CDCl}_{3}, 400 \mathrm{MHz}, \mathrm{ppm}\right): 1.50\left(\mathrm{~s}, 18 \mathrm{H}, \mathrm{H}_{14}, 2 \times t-\mathrm{Bu}\right), 2.39\left(\mathrm{~s}, 3 \mathrm{H}, \mathrm{H}_{15}\right), 2.70\left(\mathrm{~s}, 3 \mathrm{H}, \mathrm{H}_{16}\right)$, $5.64(\mathrm{~s}, 1 \mathrm{H}, \mathrm{OH}), 7.17-7.14\left(\mathrm{~m}, 2 \mathrm{H}, \mathrm{H}_{9} \& \mathrm{H}_{11}\right), 7.95-7.90\left(\mathrm{~m}, 3 \mathrm{H}, \mathrm{H}_{12}, \mathrm{H}_{3^{\prime}}\right),{ }^{13} \mathrm{C}-\mathrm{NMR}\left(\mathrm{CDCl}_{3}, 100 \mathrm{MHz}\right.$, ppm): $21.50\left(\mathrm{C}_{16}, o-\mathrm{CH}_{3}\right), 22.04\left(\mathrm{C}_{15}, p-\mathrm{CH}_{3}\right), 30.22\left(6 \mathrm{C}, \mathrm{C}_{14}, 2 \times \mathrm{C}\left(\underline{\mathrm{CH}}_{3}\right)_{3}\right), 34.55\left(2 \mathrm{C}, \mathrm{C}_{13}, 2 \times \underline{\mathrm{C}}\left(\mathrm{CH}_{3}\right)_{3}\right)$, $115.40\left(\mathrm{C}_{4}\right), 12.60\left(\mathrm{C}_{7}\right), 124.38\left(\mathrm{C}_{3}\right), 126.98\left(\mathrm{C}_{11}\right), 128.96\left(\mathrm{C}_{12}\right), 132.59\left(\mathrm{C}_{9}\right), 136.79\left(\mathrm{C}_{2}\right), 138.19\left(\mathrm{C}_{8}\right)$, $141.43\left(\mathrm{C}_{10}\right), 157.11\left(\mathrm{C}_{1}\right), 164.49 \& 164.81\left(\mathrm{C}_{5} \& \mathrm{C}_{6}\right)$. HREIMs $\left.m / z=378.2301 \mathrm{M}^{\circ+}\right]$ (calc. for $\left.\mathrm{C}_{24} \mathrm{H}_{30} \mathrm{O}_{2} \mathrm{~N}_{2}, 378.2307\right)$.

2,6-Di-tert-butyl-4-[5-(2-methylphenyl)-1,3,4-oxadiazol-2-yl] phenol (5j). The product was recrystallized from ethyl acetate to afford white crystals, $0.308 \mathrm{~g}(68.5 \%)$, m.p. $132-134{ }^{\circ} \mathrm{C}, \mathrm{IR}\left(\mathrm{KBr}, v_{\max } / \mathrm{cm}^{-1}\right)$ : $3588\left(\mathrm{OH}_{\text {phenol }}\right), 3008\left(\mathrm{CH}_{\text {aromatic }}\right), 2963\left(\mathrm{CH}_{\text {aliphatic }}\right), 1607(\mathrm{C}=\mathrm{N}), 1592,1537(\mathrm{C}=\mathrm{C}), 1238(\mathrm{C}-\mathrm{O})$, ${ }^{1} \mathrm{H}-\mathrm{NMR}\left(\mathrm{CDCl}_{3}, 400 \mathrm{MHz}, \mathrm{ppm}\right): 1.52\left(\mathrm{~s}, 18 \mathrm{H}, \mathrm{H}_{14}, 2 \times t-\mathrm{Bu}\right), 5.66(\mathrm{~s}, 1 \mathrm{H}, \mathrm{OH}), 7.44-7.34(\mathrm{~m}, 3 \mathrm{H}$, $\left.\mathrm{H}_{9}, \mathrm{H}_{10}, \mathrm{H}_{11}\right), 7.96\left(\mathrm{~s}, 2 \mathrm{H}, \mathrm{H}_{3}, \mathrm{H}_{3^{\prime}}\right), 8.02\left(\mathrm{~d}, 1 \mathrm{H}, J=7.32 \mathrm{~Hz}, \mathrm{H}_{12}\right),{ }^{13} \mathrm{C}-\mathrm{NMR}\left(\mathrm{CDCl}_{3}, 100 \mathrm{MHz}, \mathrm{ppm}\right)$ : $22.11\left(o-\mathrm{CH}_{3}\right), 30.22\left(6 \mathrm{C}, \mathrm{C}_{14}, 2 \times \mathrm{C}\left(\underline{\mathrm{CH}}_{3}\right)_{3}\right), 34.52\left(2 \mathrm{C}, \mathrm{C}_{13}, 2 \times \underline{\mathrm{C}}\left(\mathrm{CH}_{3}\right)_{3}\right), 115.53\left(\mathrm{C}_{4}\right), 123.40\left(\mathrm{C}_{7}\right)$, $124.37\left(\mathrm{C}_{3}\right), 126.21\left(\mathrm{C}_{11}\right), 128.96\left(\mathrm{C}_{12}\right), 131.03\left(\mathrm{C}_{10}\right), 131.80\left(\mathrm{C}_{9}\right), 136.80\left(\mathrm{C}_{2}\right), 138.35\left(\mathrm{C}_{8}\right), 157.14\left(\mathrm{C}_{1}\right)$, $164.32 \& 165.04\left(\mathrm{C}_{5} \& \mathrm{C}_{6}\right)$, HREIMs $m / z=364.2144\left[\mathrm{M}^{\bullet+}\right]$ (calc. for $\mathrm{C}_{23} \mathrm{H}_{28} \mathrm{O}_{2} \mathrm{~N}_{2}, 364.2151$ ).

2,6-Di-tert-butyl-4-(5-(2-chlorophenyl)-1,3,4-oxadiazol-2-yl)phenol (5k). The crude product was recrystallized from ethyl acetate to obtain white crystals. Yield $0.386 \mathrm{~g}(81 \%)$, m.p. $113-115{ }^{\circ} \mathrm{C}$, IR ( $\left.\mathrm{KBr}, v_{\max } / \mathrm{cm}^{-1}\right): 3584\left(\mathrm{OH}_{\text {phenol }}\right), 3004\left(\mathrm{CH}_{\text {aromatic }}\right), 2959\left(\mathrm{CH}_{\text {aliphatic }}\right), 1607(\mathrm{C}=\mathrm{N}), 1570,1539(\mathrm{C}=\mathrm{C})$, 1239 (C-O), ${ }^{1} \mathrm{H}-\mathrm{NMR}\left(\mathrm{CDCl}_{3}, 400 \mathrm{MHz}, \mathrm{ppm}\right): 1.48\left(\mathrm{~s}, 18 \mathrm{H}, \mathrm{H}_{14}, 2 \times t\right.$-Bu), $5.66(\mathrm{~s}, 1 \mathrm{H}, \mathrm{OH})$, 7.38-7.46 (m, 2H, H $\left.\mathrm{H}_{10}, \mathrm{H}_{11}\right), 7.53\left(\mathrm{~d}, 1 \mathrm{H}, J=8.04 \mathrm{~Hz}, \mathrm{H}_{12}\right), 7.95\left(\mathrm{~s}, 2 \mathrm{H}, \mathrm{H}_{3}, \mathrm{H}_{3^{\prime}}\right), 8.05(\mathrm{~d}, 1 \mathrm{H}, J=6.32 \mathrm{~Hz}$, $\left.\mathrm{H}_{9}\right),{ }^{13} \mathrm{C}-\mathrm{NMR}\left(\mathrm{CDCl}_{3}, 100 \mathrm{MHz}, \mathrm{ppm}\right): 30.27\left(6 \mathrm{C}, \mathrm{C}_{14}, 2 \times \mathrm{C}\left(\underline{\mathrm{CH}}_{3}\right)_{3}\right), 34.61\left(2 \mathrm{C}, \mathrm{C}_{13}, 2 \times \underline{\mathrm{C}}\left(\mathrm{CH}_{3}\right)_{3}\right)$, $115.18\left(\mathrm{C}_{4}\right), 123.65\left(\mathrm{C}_{7}\right), 124.61\left(\mathrm{C}_{3}\right), 127.21\left(\mathrm{C}_{11}\right), 131.33\left(\mathrm{C}_{12}\right), 132.32\left(\mathrm{C}_{9}\right), 133.14\left(\mathrm{C}_{8}\right)$, $136.79\left(\mathrm{C}_{9}\right), 136.94\left(\mathrm{C}_{2}\right), 157.28\left(\mathrm{C}_{1}\right), 162.55 \& 166.04\left(\mathrm{C}_{5} \& \mathrm{C}_{6}\right)$. HREIMs $m / z=384.1600\left[\mathrm{M}^{\bullet+}\right]$ (calc. for $\mathrm{C}_{22} \mathrm{H}_{25} \mathrm{O}_{2} \mathrm{~N}_{2} \mathrm{Cl}, 384.1605$ ).

\section{Conclusions}

A series of new 1,3,4-oxadiazole compound incorporating hindered phenol moities were successfully synthesized and characterized. All of the new compounds were screened for antioxidant activity using 
the FRAP and DPPH assays. The substituents on ring $\mathrm{C}$ demonstrated a significant role in improving or negating the antioxidant activity of the compounds. The analogues incorporating electron releasing substituents exhibited high antioxidant activity, whereas those with electron withdrawing substituent demonstrated reduced antioxidant activity.

\section{Supplementary Materials}

Supplementary materials can be accessed at: http://www.mdpi.com/1420-3049/19/3/3436/s1.

\section{Acknowledgments}

We would like to thank the University of Malaya for a UMRG grant (RG149-11AFR) and a PPP grant (PS345-2009B) and the Ministry of Higher Education of Malaysia for supporting this study. We are also grateful to Amir Atto for his contributions and advice and to Noel F. Thomas for proofreading the manuscript.

\section{Author Contributions}

All authors contributed equally for the manuscript. Raied M. Shakir (PhD candidates), Mahmood Ameen Abdulla (DPPH and FRAP assays).

\section{Conflicts of Interest}

The authors report no conflicts of interest. The authors alone are responsible for the content and writing of the paper.

\section{References}

1. Kar, S.; Subbaram, S.; Carrico, P.M.; Melendez, J.A. Redox-control of matrix metalloproteinase-1: A critical link between free radicals, matrix remodeling and degenerative disease. Respir. Physiol. Neurobiol. 2010, 174, 299-306.

2. Khalil, Z.; Khodr, B. A role for free radicals and nitric oxide in delayed recovery in aged rats with chronic constriction nerve injury. Free Radic. Biol. Med. 2001, 31, 430-439.

3. Ziakas, G.N.; Rekka, E.A.; Gavalas, A.M.; Eleftheriou, P.T.; Kourounakis, P.N. New analogues of butylated hydroxytoluene as anti-inflammatory and antioxidant agents. Bioorg. Med. Chem. 2006, 14, 5616-5624.

4. Yehye, W.A.; Abdul Rahman, N.; Alhadi, A.A.; Khaledi, H.; Ng, S.W.; Ariffin, A. Butylated hydroxytoluene analogs: Synthesis and evaluation of their multipotent antioxidant activities. Molecules 2012, 17, 7645-7665.

5. Ruiz, J.; Pẻrez, C.; Pouplana, R. QSAR study of dual cyclooxygenase and 5-lipoxygenase inhibitors 2,6-di-tert-butylphenol derivatives. Bioorg. Med. Chem. 2003, 11, 4207-4216.

6. Mullican, M.D.; Wilson, M.W.; Connor, D.T.; Kostlan, C.R.; Schrier, D.J.; Dyer, R.D. Design of 5-(3,5-di-tert-butyl-4-hydroxyphenyl)-1,3,4-thiadiazo-1 1,3,4 -oxadiazoles and -1,2,4-triazoles as orally-active, nonulcerogenic antiinflammatory agents. J. Med. Chem. 1993, 36, 1090-1099. 
7. Moore, G.G.; Swingle, K.F. 2,6-Di-tert-butyl-4-(2'-thenoyl)phenol(R-830): A novel nonsteroidal anti-inflammatory agent with antioxidant properties. Agents Actions 1982, 12, 674-683.

8. Ye, X.; Zhou, W.; Li, Y.; Sun, Y.; Zhang, Y.; Ji, H.; Lai, Y. Darbufelone, a novel anti-inflammatory drug, induces growth inhibition of lung cancer cells both in vitro and in vivo. Cancer Chemother. Pharmacol. 2010, 66, 277-285.

9. Sagar, B.H.; Stephen, M. Antioxidants during anticancer therapy. Focus Altern. Complement. Ther. 2004, 9, 96-106.

10. Jeong, T.-S.; Kim, K.S.; Kim, J.-R.; Cho, K.-H.; Lee, S.; Lee, W.S. Inhibitory efects of multi-substituted benzylidenethiazolidine-2,4-diones on LDL oxidation. Bioorg. Med. Chem. 2004, 12, 4017-4023.

11. Song, Y.; Connor, D.T.; Doubleday, R.; Sorenson, R.J.; Sercel, A.D.; Unangst, P.C.; Roth, B.D.; Gilbertsen, R.B.; Chan, K.; Schrier, D.J.; et al. Synthesis, structure-activity relationships, and in vivo evaluations of substituted di-tert-butylphenols as a novel class of potent, selective, and orally active cyclooxygenase- 2 inhibitors. 1. Thiazolone and oxazolone series. J. Med. Chem. 1999, 42, 1151-1160.

12. Cuadro, A.M.; Valenciano, J.S.; Vaquero, J.J.; Alvarez-Builla, J.; Sunkel, C.; de Casa-Juana, M.F.; Ortega, M.P. Synthesis and biological evaluation of 2,6-di-tert-butylphenol hydrazones as 5-lipoxygenase inhibitors. Bioorg. Med. Chem. 1998, 6, 173-180.

13. Nonhebel, D.C.; Walton, J.C. Free-Radical Chemistry, Structure and Mechanism; Cambridge University Press: Cambridge, UK, 1974; p. 477.

14. Hung, C.-Y.; Yen, G.-C. Antioxidant activity of phenolic compounds isolated from mesona procumbens hemsl. J. Agric. Food Chem. 2002, 50, 2993-2997.

15. De Oliveira, C.S.; Lira, B.F.; Barbosa-Filho, J.M.; Lorenzo, J.G.F.; de Athayde-Filho, P.F. Synthetic approaches and pharmacological activity of 1,3,4-oxadiazoles: A review of the literature from 2000-2012. Molecules 2012, 17, 10192-10231.

16. De Oliveira, C.S.; Lira, B.F.; dos Santos Falcão-Silva, V.; Siqueira-Junior, J.P.; Barbosa-Filho, J.M.; de Athayde-Filho, P.F. Synthesis, molecular properties prediction, and anti-staphylococcal activity of $N$-acylhydrazones and new 1,3,4-oxadiazole derivatives. Molecules 2012, 17, 5095-5107.

17. El Sadek, M.; Hassan, S.; Abdelwahab, H.; Yacout, G. Synthesis and bioassay of a new class of furanyl-1,3,4-oxadiazole derivatives. Molecules 2013, 18, 8550-8562.

18. Musad, E.A.; Mohamed, R.; Ali Saeed, B.; Vishwanath, B.S.; Lokanatha Rai, K.M. Synthesis and evaluation of antioxidant and antibacterial activities of new substituted bis(1,3,4-oxadiazoles), 3,5-bis(substituted) pyrazoles and isoxazoles. Bioorg. Med. Chem. Lett. 2011, 21, 3536-3540.

19. Maheshwari, R.; Chawla, P.; Saraf, S. Comparison between antioxidant activity of 2,5-disubstituted 1,3,4-oxadiazoles containing heteroaromatic ring and aromatic ring at 2nd position. Med. Chem. Res. 2011, 20, 1650-1655.

20. Silverstein, R.; Webster, F. Spectromeetric Identification Of Organic Compounds; John Wiley \& Sons Inc.: New York, NY, USA, 1998; pp. 90-91.

21. Frański, R.; Eitner, K.; Schroeder, G. Mass spectrometric study of some protonated and lithiated 2,5-disubstituted-1,3,4-oxadiazoles. J. Am. Soc. Mass Spectrom. 2003, 14, 289-294. 
22. Frański, R.; Schroeder, G.; Rybachenko, V.; Szwajka, O.P. Loss of isocyanic acid from the internal oxadiazole ring of protonated molecules of some 2,5-diaryl-1,3,4-oxadiazoles. Rapid Commun. Mass Spectrom. 2002, 16, 390-395.

23. Frański, R.; Gierczyk, B.; Schroeder, G. Mass spectrometric fragmentation pathways of isotope labeled 2,5-disubstituted-1,3,4-oxadiazoles and thiadiazoles. Int. J. Mass Spectrom. 2004, 231, 47-49.

24. Benzie, I.F.; Strain, J.J. The Ferric Reducing Ability of Plasma (FRAP) as a measure of "antioxidant power": The FRAP assay. Anal. Biochem. 1996, 239, 70-76.

25. Rustaiyan, A.; Javidnia, K.; Farjam, M.H.; Aboee-Mehrizi, F.; Ezzatzadeh, E. Antimicrobial and antioxidant activity of the Ephedra sarcocarpa growing in Iran. J. Med. Plants Res. 2011, 5, 4251-4255.

26. Gerhäuser, C.; Klimo, K.; Heiss, E.; Neumann, I.; Gamal-Eldeen, A.; Knauft, J.; Liu, G.-Y.; Sitthimonchai, S.; Frank, N. Mechanism-based in vitro screening of potential cancer chemopreventive agents. Mutat. Res. Fundam. Mol. Mech. Mutagen. 2003, 523-524, 163-172.

27. Shahidi, F. Natural Antioxidants: Chemistry, Health Effects, and Applications; AOCS Press: Champaign, IL, USA, 1997; p. 18.

28. Simić, A.; Manojlović, D.; Šegan, D.; Todorović, M. Electrochemical behavior and antioxidant and prooxidant activity of natural phenolics. Molecules 2007, 12, 2327-2340.

29. Moalin, M.; Strijdonck, G.P.F.; Beckers, M.; Hagemen, G.J.; Borm, P.J.; Bast, A.; Haenen, G.R. A planar conformation and the hydroxyl groups in the $\mathrm{B}$ and $\mathrm{C}$ rings play a pivotal role in the antioxidant capacity of quercetin and quercetin derivatives. Molecules 2011, 16, 9636-9650.

30. Torres, R.; Urbina, F.; Morales, C.; Modak, B.; Monache, F.D. Antioxidant properties of lignans and ferulic acid from the resinous exudate of larrea nitida. J. Chil. Chem. Soc. 2003, doi:10.4067/S0717-97072003000300012.

31. Lucarini, M.; Pedrielli, P.; Pedulli, G.F.; Cabiddu, S.; Fattuoni, C. Bond dissociation energies of O-H bonds in substituted phenols from equilibration studies. J. Org. Chem. 1996, 61, 9259-9263.

32. Inami, K.; Iizuka, Y.; Furukawa, M.; Nakanishi, I.; Ohkubo, K.; Fukuhara, K.; Fukuzumi, S.; Mochizuki, M. Chlorine atom substitution influences radical scavenging activity of 6-chromanol. Bioorg. Med. Chem. 2012, 20, 4049-4055.

33. Huang, D.; Ou, B.; Prior, R.L. The chemistry behind antioxidant capacity assays. J. Agric. Food Chem. 2005, 53, 1841-1856.

34. Brand-Williams, W.; Cuvelier, M.E.; Berset, C. Use of a free radical method to evaluate antioxidant activity. LWT Food Sci. Technol. 1995, 28, 25-30.

Sample Availability: Samples of the compounds $\mathbf{5 a}-\mathbf{k}$ are available from the authors.

(C) 2014 by the authors; licensee MDPI, Basel, Switzerland. This article is an open access article distributed under the terms and conditions of the Creative Commons Attribution license (http://creativecommons.org/licenses/by/3.0/). 